\title{
Lâminas de irrigação e coberturas do solo sobre a incidência da mancha fisiológica e produtividade do mamão "Golden"
}

\author{
Irrigation dosages and soil coverings in the incidence of skin freckles and yield components \\ of papaya 'Golden'
}

\author{
Aroldo Gomes Filho $^{\mathrm{I}^{*}}$ Jurandi Gonçalves de Oliveira ${ }^{\mathrm{I}}$ Alexandre Pio Viana ${ }^{\mathrm{I}}$ \\ Messias Gonzaga Pereira ${ }^{\mathrm{I}}$
}

\section{RESUMO}

Nesse experimento, avaliou-se o efeito de diferentes lâminas de irrigação e coberturas do solo sobre aspectos qualitativos e de produção do mamão cv. "Golden" no período de dezembro de 2003 a novembro de 2004. Utilizou-se delineamento em blocos casualizados, com três repetições, em esquema fatorial. Os resultados encontrados demonstram uma alta correlação entre a época de colheita com a incidência da mancha fisiológica e as variáveis de produção. Com relação à mancha fisiológica do mamão (MFM), confirmou-se o aspecto sazonal de incidência, sendo que a cv. "Golden" apresentou a maior incidência do distúrbio no mês de setembro. Com relação às coberturas de solo, a cobertura morta se mostrou promissora para os fatores em estudo, ao contrário da cobertura verde com a leguminosa Arachis pintoe, pois a mesma, provavelmente, competiu por água e nutrientes com o mamoeiro, acarretando, assim, redução na sua produtividade.

Palavras-chave: Carica papaya L., manejo alternativo, distúrbio fisiológico.

\section{ABSTRACT}

In this experiment the effect of different irrigation rates and soil coverings on qualitative aspects as well as yield components of the papaya cv. 'Golden' during the period December 2003 to November 2004 were evaluated. A randomized complete block design was used with three replications in a factorial scheme. The results demonstrate high correlation involving the factors harvest season, incidence of skin freckles and yield components. With relation to skin freckles a seasonal incidence was confirmed, showing that for $\mathrm{cv}$. 'Golden', the major incidence of the disturbance was verified in September. The mulching treatment was promising for the factors studied, in contrast to the green covering using the leguminosae Arachis pintoe, due to competition with the papaya trees for water and nutrients, causing a reduction in the yield components.
Key words: Carica papaya L., alternative handling, physiological disturbance.

\section{INTRODUÇÃO}

Atualmente, o Brasil ocupa o primeiro lugar em produção de mamão no mundo, com 1.714 .590 toneladas produzidas no ano de 2003 (IBGE, 2005). Os estados da Bahia e Espírito Santo destacam-se na produção nacional, sendo este último responsável por 80\% das exportações de mamão do Brasil (ALVES, 2003). Para as exportações, os frutos mais adequados são os do grupo Solo, por possuírem peso e tamanho menores do que os frutos do grupo Formosa, sendo essas características bastante apreciadas pelos consumidores.

Porém, os frutos das cultivares do grupo Solo são altamente susceptíveis à Mancha Fisiológica do Mamão (MFM), o que restringe as suas exportações. Este problema foi solucionado, em parte, a partir de uma mutação ocorrida na cultivar "Improved Sunrise Solo” nos pomares da empresa Caliman Agrícola S/A, em Linhares-ES, sendo este material selecionado e propagado comercialmente com o nome de "Golden". A cultivar "Golden" apresenta frutos e folhas de coloração verde-clara, sendo assim denominada por MARIN \& GOMES (2000) como "acentuadamente aclorofilada”. Embora de produtividade e qualidade de polpa inferior às demais cultivares do grupo Solo, a sua casca é lisa e bastante tolerante à MFM, o que a

'Universidade Estadual do Norte Fluminense Darcy Ribeiro (UENF), Laboratório de Melhoramento Genético Vegetal, 28013-602,

Campos dos Goytacazes, RJ, Brasil. *Autor para correspondência. E-mail: agomes@uenf.br. 
torna, atualmente, a cultivar de maior aceitação no mercado externo.

A variedade "Golden” originalmente era bastante tolerante à MFM. Entretanto, durante a extração de material propagativo (sementes) a tendência tem sido no sentido de selecionar plantas mais produtivas, mais vigorosas (de coloração verde mais intensa, etc.), com características qualitativas de frutos superiores. Essa prática, repetida sistematicamente, acaba por selecionar materiais mais susceptíveis à MFM, uma vez que essas plantas mais produtivas são, também, genótipos mais próximos do material de origem, ou seja, o "Sunrise Solo 72/12". Com isso, os frutos da variedade "Golden" têm demonstrado cada vez menor tolerância à MFM, fato este preocupante em se tratando da comercialização para o mercado externo.

A ocorrência da MFM provavelmente está associada com a ruptura dos laticíferos do mamão com conseqüente extravasamento do látex no tecido subepicárpico; este fato, segundo ELOISA et al. (1994) e KAISER et al. (1996), desencadearia o distúrbio. A ruptura dos laticíferos dos frutos poderia ocorrer em função de alterações bruscas na pressão interna desses condutores. Esse aumento na pressão interna dos laticíferos pode estar associado a fatores do ambiente como o excesso de água no solo (ELOISA et al., 1994), as baixas temperaturas ou as amplitudes térmicas diárias muito altas (DOWNTON, 1981) ou, ainda, a alta umidade do ar (ELOISA et al., 1994). Todos esses fatores do ambiente são, certamente, modulados em certo grau pelo fator genético (OLIVEIRA et al., 2005).

Com base nessas premissas, foi sugerido um manejo alternativo na cultura do mamão com diferentes lâminas de irrigação e coberturas do solo. Tal manejo, acredita-se, promoveria diferentes pressões internas nos laticíferos dos frutos, o que ocasionaria a menor ou maior incidência do distúrbio. $\mathrm{O}$ presente trabalho teve por objetivo a aplicação de manejo alternativo de água de irrigação e de cobertura do solo na cultura do mamoeiro, visando a minimizar a ocorrência de estresses sobre o mamoeiro, com conseqüente redução na incidência da MFM.

\section{MATERIAL E MÉTODOS}

O experimento foi desenvolvido durante doze meses, no período de dezembro/2003 a novembro/ 2004, na Empresa Caliman Agrícola S/A, na fazenda Romana, que está localizada no Município de Linhares, na Região Norte do Estado do Espírito Santo, sendo a fazenda integrante da Microrregião 205. A Fazenda Romana fica localizada na latitude $19^{\circ} 15^{\prime}$ S e na longitude de $39^{\circ} 51^{\prime} \mathrm{O}$. O clima na microrregião 205 classifica-se como Awi na Escala de Koopen (tropical úmido), que se caracteriza por um verão úmido e um inverno seco. A precipitação média anual, histórica, foi estimada em 1.224,3mm, no período de 1975 a 1995, enquanto a temperatura média foi de $23^{\circ} \mathrm{C}$ e a umidade relativa do ar de $83,5 \%$. No período experimental, a precipitação média anual foi de $1.738,9 \mathrm{~mm}$, a temperatura média foi de $23,8^{\circ} \mathrm{C}$ e a umidade relativa do ar de $84,3 \%$. Os solos da Fazenda Romana são em sua maioria classificados como Podzólicos Vermelho Amarelo, textura argilo arenosa, fase floresta subperenifólia, relevo plano a suavemente ondulado (platôs litorâneos). Com relação à fertilidade, o solo possui as seguintes características: $\mathrm{P}, 34 \mathrm{mg} \mathrm{dm}^{-3} ; \mathrm{K}, 55 \mathrm{mg} \mathrm{dm}^{-3}$; S, 6mg dm³; pH em água, 6,3; matéria orgânica, 3,7dag $\mathrm{Kg}^{-1}$; relação $\mathrm{Ca} / \mathrm{Mg}$ de 4; relação $\mathrm{Ca} / \mathrm{K}$ de 19,9; relação $\mathrm{Mg} / \mathrm{K}$ de 5; CTC efetiva, 3,6 $\mathrm{cmol}_{\mathrm{c}} \mathrm{dm}^{-3}$ e saturação de bases, 66,9\%. Além disso, o solo em questão apresentase totalmente sem restrições para o uso agrícola, não necessitando de práticas especiais de manejo para controle de erosão.

Foram utilizadas plantas com cerca de 18 meses de idade da cultivar “Golden”, em plena produção, dispostas em fileiras duplas (3,6 x 2,0 x 2,0m) com irrigação por microaspersão, com faixa molhada contínua. As adubações de cobertura foram realizadas mensalmente utilizando-se $160 \mathrm{~g}$ de sulfato de amônio e $80 \mathrm{~g}$ de cloreto de potássio. Com relação ao controle fitossanitário, durante o período experimental houve o monitoramento das principais pragas, sendo feitas pulverizações com fungicidas (controle de antracnose e pinta preta) e inseticidas (controle de ácaros e cochonilhas) quando necessárias.

Os tratamentos utilizados no experimento consistiram de três tipos de cobertura de solo: $\mathrm{C}_{0}$, sem cobertura - solo nu; $\mathrm{C}_{1}$, cobertura morta - lâmina $(\approx 5 \mathrm{~cm})$ de capim, seco, picado e $\mathrm{C}_{2}$, cobertura verde - amendoim forrageiro (Arachis pintoe), associado a três lâminas de irrigação: $\mathrm{L}_{0}, 50 \%$ de $\mathrm{ET}_{0}$; $\mathrm{L}_{1}, 100 \%$ de $\mathrm{ET}_{0}$ e $\mathrm{L}_{2}, 150 \%$ de $\mathrm{ET}_{0}$, sendo a $\mathrm{ET}_{0}$ determinada através da equação de Penman-Monteith.

Os frutos foram colhidos no estádio dois de maturação (1/4 maduro), sendo avaliadas as seguintes características: 1) índice de ocorrência da MFM, através de análise subjetiva, pela qual foram atribuídas notas para a incidência da MFM, de acordo com OLIVEIRA et al. (2005) (nenhuma mancha, nota 0; muito baixa ocorrência, nota 1 ; baixa ocorrência, nota 2; média ocorrência, nota 3; alta ocorrência, nota 4 e, finalmente, a nota 5 para muito alta ocorrência da mancha); 2) peso médio de seis frutos por parcela - obtido em balança semi-analítica; 3) número médio de frutos por planta- 
por contagem de todos os frutos de três plantas por parcela a cada três meses e 4) a produtividade - que foi determinada pela multiplicação do número médio de frutos por planta versus o peso médio de seis frutos. Os resultados da produtividade foram expressos em $\mathrm{T}$ ha $^{-1}$, considerando-se uma densidade média de 1.785 plantas por hectare.

O experimento foi instalado seguindo delineamento experimental em blocos casualizados com três repetições, em esquema de parcelas subdivididas, com o fator irrigação disposto na parcela e o fator cobertura disposto na subparcela, representando as três coberturas de solo e as três lâminas de irrigação, totalizando 27 parcelas com a unidade experimental composta de três plantas por parcela, utilizando-se dois frutos por planta. Para as avaliações da incidência da MFM, os resultados foram expressos através da média dos diversos tratamentos, sendo três lâminas de irrigação, três coberturas de solo e três repetições com uma unidade experimental de seis frutos por parcela, totalizando assim 162 frutos por período de avaliação. Para a análise relativa a notas da MFM, procedeu-se à análise de variância e ao teste de desvio padrão de Friedman a 1\% de probabilidade.

Para a análise dos dados de produtividade, utilizou-se o programa Genes (CRUZ, 2001), sendo os resultados interpretados por meio de análises de variância com teste F. Quando as interações foram significativas, as mesmas foram desdobradas, sendo as médias comparadas pelo teste Tukey. Em todas as análises estatísticas adotou-se 5\% de probabilidade de erro.

\section{RESULTADOS E DISCUSSÃO}

A variável MFM mostrou-se dependente da época do ano em que os frutos foram colhidos. Entretanto, não houve significância para as lâminas de irrigação e as coberturas do solo.

Os resultados (Figura 1) demonstram que o período de outubro a agosto apresentou-se, como o esperado, com baixa ocorrência da MFM. Com isso, os valores do nível de ocorrência do distúrbio ficaram muito baixos, com valores médios próximos à nota 1 , com o mês de maio apresentando notas próximas a 0 , ou seja, nenhuma ocorrência de incidência do distúrbio. Isso demonstra que os tratamentos adotados pouco influenciaram na ocorrência do distúrbio nos meses citados, visto que a incidência da MFM apresenta-se num padrão sazonal de ocorrência. Segundo CRUZ LIMA (2003), a MFM apresenta uma maior incidência nos meses de agosto e setembro. Os resultados demonstrados neste experimento estão similares aos observados por esse autor, pois encontrou-se a maior

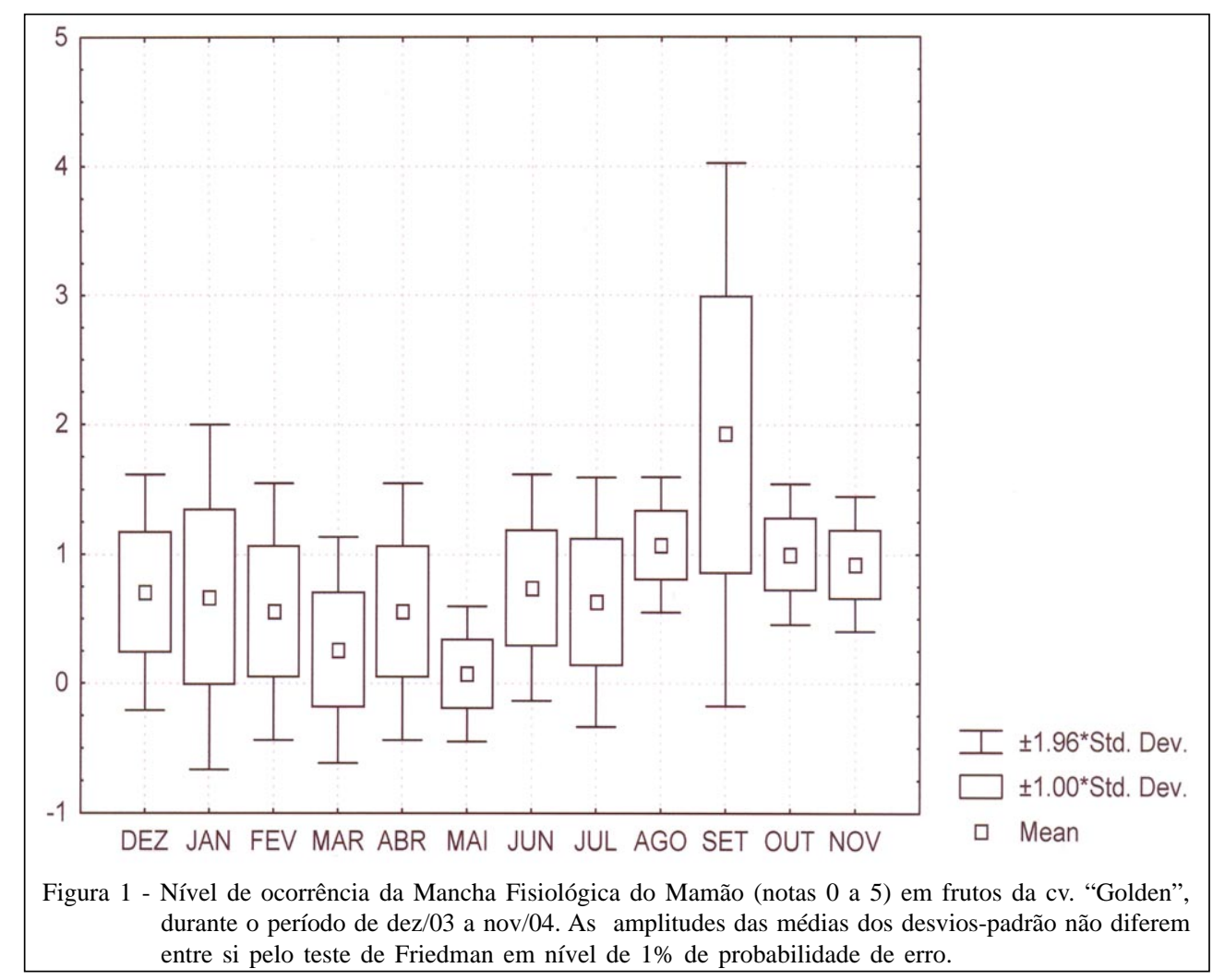

Ciência Rural, v.37, n.6, nov-dez, 2007. 
incidência do distúrbio da MFM no mês de setembro. No mês de maior ocorrência da MFM (setembro), a amplitude térmica observada foi de $10,9^{\circ} \mathrm{C}$. Este valor é o maior registrado para o período de avaliação (variação entre 7,2 e $10,9^{\circ} \mathrm{C}$ ), o qual poderia estar correlacionado com a ocorrência do distúrbio. De acordo com DOWNTON (1981), baixas temperaturas diurnas ou amplitudes térmicas diárias muito altas ocasionam maior pressão de turgescência nos vasos laticíferos de Nerium oleander. Segundo esse autor, o aumento na pressão dentro dos vasos foi duas vezes maior, quando da ocorrência das baixas temperaturas atmosféricas, em relação à época com elevadas temperaturas do ar. Neste experimento, o mês de setembro registrou a maior amplitude térmica diária, condição essa, segundo DOWNTON (1981), propícia a uma maior pressão de turgescência nos vasos laticíferos. Essa maior pressão nos vasos laticíferos do fruto seria a causa para a maior ocorrência da MFM no respectivo período, o que, em parte, comprova uma possível correlação entre a amplitude térmica diária e a incidência da MFM.

O número de frutos (NF) foi influenciado pelo período do ano em que os mesmos foram colhidos. Os resultados (Tabela 1) mostram a efetividade da alteração do manejo da cultura sobre essa variável. O NF mostrou-se significativamente dependente das lâminas de irrigação e coberturas do solo aplicadas. Os resultados da tabela 1 demonstram superioridade do tratamento com o solo nu para as diferentes lâminas, pois este tratamento foi estatisticamente superior nos meses de março e setembro para as lâminas de 50 e $100 \%$ da ETo. Estes resultados contradizem uma

Tabela 1 - Estimativa do número médio de frutos (NF), peso médio de frutos (PF) e da produtividade (PR) do trimestre em $t$ ha ${ }^{-1}$ para mamão da cv. "Golden", durante o período de dez/03 a set/04, em função das lâminas de irrigação e coberturas do solo aplicadas: capim seco (CM), Arachis pintoe (CV) e solo nu (SN). As épocas de avaliação foram: dezembro (D), março (M), junho (J) e setembro (S).

\begin{tabular}{|c|c|c|c|c|c|c|}
\hline \multirow[b]{2}{*}{ Variáveis $^{1}$} & \multirow[b]{2}{*}{ Lâminas } & \multirow[b]{2}{*}{ Coberturas } & \multicolumn{4}{|c|}{ Épocas } \\
\hline & & & $\mathrm{D}$ & M & $\mathrm{J}$ & $\mathrm{S}$ \\
\hline & & CM & $27,98 \mathrm{Ba}$ & $21,02 \mathrm{Cb}$ & $33,29 \mathrm{ABa}$ & $37,44 \mathrm{Ab}$ \\
\hline \multirow[t]{8}{*}{ NF } & $50 \%$ Eto & $\mathrm{CV}$ & $17,81 \mathrm{Bb}$ & $19,22 \mathrm{Bb}$ & 33,00 Aa & 28,83 Ac \\
\hline & & $\mathrm{SN}$ & 23,69 Ca & 28,83 Ca & 36,03 Ba & 44,29 Аа \\
\hline & & CM & 21,33 Ca & $15,17 \mathrm{Cb}$ & $33,67 \mathrm{Ba}$ & 44,28 Аа \\
\hline & $100 \%$ Eto & $\mathrm{CV}$ & $22,09 \mathrm{Ba}$ & $12,04 \mathrm{Cb}$ & 32,61 Аа & $37,33 \mathrm{Ab}$ \\
\hline & & $\mathrm{SN}$ & $22,50 \mathrm{Ca}$ & 22,83 Ca & $34,44 \mathrm{Ba}$ & 41,78 Aab \\
\hline & & CM & $27,12 \mathrm{Ba}$ & 11,78 Cab & $30,02 \mathrm{Ba}$ & 38,74 Aab \\
\hline & $150 \%$ Eto & $\mathrm{CV}$ & $17,64 \mathrm{Bb}$ & 9,03 Cb & 27,33 Аа & $33,00 \mathrm{Ab}$ \\
\hline & & $\mathrm{SN}$ & $27,49 \mathrm{Ba}$ & $16,24 \mathrm{Ca}$ & 29,91 Ва & 42,40 Аа \\
\hline \multirow[t]{4}{*}{$\mathrm{PF}^{2}$} & & & $374.08 \mathrm{~B}$ & 363.02 B & 473.72 A & $462.59 \mathrm{~A}$ \\
\hline & & $\mathrm{CM}$ & $20,16 \mathrm{Ba}$ & 14,55 Bab & $30,67 \mathrm{Ab}$ & 32,67 Аа \\
\hline & $50 \%$ Eto & $\mathrm{CV}$ & $10,76 \mathrm{Cb}$ & $10,11 \mathrm{Cb}$ & 33,83 Aab & $22,92 \mathrm{Bb}$ \\
\hline & & $\mathrm{SN}$ & 16,28 Bab & $17,87 \mathrm{Ba}$ & 36,71 Аа & 34,38 Аа \\
\hline \multirow[t]{6}{*}{ PR } & & $\mathrm{CM}$ & $13,92 \mathrm{Ca}$ & 10,36 Cab & $29,89 \mathrm{Ba}$ & 36,69 Аа \\
\hline & $100 \%$ Eto & $\mathrm{CV}$ & $14,34 \mathrm{Ba}$ & 6,81 Cb & 29,17 Аа & $28,22 \mathrm{Ab}$ \\
\hline & & SN & $14,73 \mathrm{Ca}$ & $13,74 \mathrm{Ca}$ & $29,06 \mathrm{Ba}$ & 37,48 Аа \\
\hline & & $\mathrm{CM}$ & $19,45 \mathrm{Ba}$ & 8,04 Ca & $25,48 \mathrm{Ba}$ & 34,46 Аа \\
\hline & $150 \%$ Eto & $\mathrm{CV}$ & $12,99 \mathrm{Bb}$ & 6,32 Ca & $21,85 \mathrm{Aa}$ & $27,26 \mathrm{Ab}$ \\
\hline & & SN & 17,24 Cab & $10,89 \mathrm{Ca}$ & 25,65 Ba & 33,03 Aab \\
\hline
\end{tabular}

As médias não seguidas pela mesma letra, minúscula na coluna e maiúscula na linha, diferem entre si pelo teste de Tukey em nível de 5\% de probabilidade de erro.

${ }^{1} \mathrm{CV}(\%)$ para $\mathrm{NF}=18,61$; para $\mathrm{PF}=11,32$; para $\mathrm{PR}=24,12$.

${ }^{2}$ Os valores de PF são relativos à média dos tratamentos aplicados.

Ciência Rural, v.37, n.6, nov-dez, 2007. 
primeira expectativa, pois acreditava-se que os tratamentos com as coberturas de solo propiciariam um maior NF. Entretanto, vale ressaltar que a área de implantação do referido experimento ainda não possuía um histórico de uso de cobertura de solo, tendo sido o mesmo implantado aos seis meses de idade da cultura.

É razoável crer que, para a cultura ser beneficiada, em termos de aumento no número de frutos pela melhoria nas condições do solo, com maior disponibilidade hídrica e nutricional, seriam necessários alguns ciclos da cultura. Portanto, não seria possível, ainda, a partir de sua implantação, verificar ganhos significativos em tempo relativamente curto. Além disso, no período do experimento, dez/03 a nov/04, houve um grande acréscimo no conteúdo hídrico do solo devido aos altos índices pluviométricos ocorridos na região (Figura 2). Este fato seria responsável pelo acúmulo de grande quantidade de água nos tratamentos com coberturas, dificultando assim a absorção de nutrientes pela cultura por falta de aeração, com conseqüências, potenciais, de aumento nos níveis de esterilidade de flores (ALMEIDA et al., 2003). Além disso, segundo AWADA \& IKEDA(1975), um aumento no teor de água disponível no solo contribui para o aumento na incidência de flores carpelóides, o que afetaria o NF, uma vez que contavam-se apenas os frutos que possuíam padrão para serem comercializados.

De modo geral, houve uma queda no NF entre os meses de dezembro e março. Essa queda foi consistente em todas as lâminas quando da associação com as coberturas de solo. É provável que tal queda no índice NF, no referido período, seja um reflexo do aumento na incidência de esterilidade e/ou abortamento de flores. Este abortamento seria uma conseqüência da queda na umidade relativa registrada no período entre os meses de setembro e novembro, ou seja, no período em que houve a fecundação das flores que geraram os frutos colhidos entre dezembro e março. Segundo COUTO \& NACIF (1999), a baixa umidade relativa, em qualquer período do ano, é um fator desencadeador de aumento de flores masculinas e de flores estéreis, o que também compromete o NF.

Os fatores ambientais contribuem diretamente na expressão do sexo; dentre eles, destacam-se: nutrição mineral, fatores edáficos, luz, temperatura e agentes químicos (FRANKEL \& GALUN, 1977). Além desses fatores citados pelos autores acima, a água também é um fator importantíssimo na expressão do sexo em mamoeiro. ALMEIDA (2000), trabalhando com diferentes lâminas de irrigação na cultura do mamão, observou que essa espécie, quando exposta ao déficit ou ao excesso hídrico, apresenta um aumento na incidência de esterilidade de flores, o que, em conseqüência, resultaria em um menor número de frutos. ALMEIDA (2000) ainda retrata a importância da água no desenvolvimento do fruto, pois o autor encontrou um crescimento linear para o NF de mamão para lâminas de reposição de até $160 \%$ da $\mathrm{ET}_{\text {. }}$. Contudo, no presente trabalho, verificou-se padrão diferente, pois, no período seco do ano, o NF aumentou, atingindo valores superiores. Entretanto, não houve diferenças entre as lâminas de irrigação.

O tipo de lâmina de irrigação e cobertura de solo utilizado neste experimento não interferiu nos valores do peso médio dos frutos (PF). Apenas observouse significância, para a variável $\mathrm{PF}$, quanto ao período de colheita dos frutos.

Os resultados relativos ao PF (Tabela 1) mostram que, ao longo do período de avaliação, os menores valores de PF foram verificados no período de dezembro a março, com as maiores médias nos meses de junho a setembro. Esses resultados estão próximos aos encontrados por MARIN \& SILVA (1996), que observaram, no Estado do Espírito Santo, a ocorrência de menores pesos dos frutos nos meses de agosto a março e maiores entre os meses de junho a julho para frutos de mamão do grupo Solo.

Figura 2 - Balanço hídrico durante o período de dezembro/03 a novembro/04 em função da precipitação e dos tratamentos aplicados. 
De acordo com Berilli (2006), frutos de mamão "UC01" colhidos no período de verão são mais precoces, atingindo o ponto de colheita, aproximadamente, quatro meses após a antese, contra seis meses para o ponto de colheita dos frutos desenvolvidos no período de inverno. Portanto, esses frutos ficaram ligados menos tempo à planta-mãe, com menor translocação de fotoassimilados para os mesmos, o que poderia refletir em um menor ganho de peso do fruto, como o verificado neste experimento. Ainda nesse sentido, os resultados aqui verificados mostram que os maiores valores de peso do fruto foram registrados no período de inverno. Os frutos colhidos neste período ficaram, aproximadamente, seis meses ligados à planta, ou seja, os mesmos receberam mais fotoassimilados e conseqüentemente ganharam mais peso (OLIVEIRA, 1999).

A alteração do manejo da cultura mostrouse efetiva para a variável produtividade do mamoeiro cv. "Golden" ao longo do período de colheita (Tabela 1). Os tratamentos com lâminas de irrigação e cobertura do solo mostraram-se, significativamente, eficientes em alterar os índices de produtividade da lavoura; contudo, não se pode concluir sobre uma tendência concreta. Provavelmente, a alta precipitação na maior parte do período experimental tenha influenciado os resultados (Figura 2), prejudicando assim a análise precisa da influência das lâminas de irrigação e coberturas do solo no mamoeiro. Isso porque, segundo a figura 2, apenas nos meses de agosto e setembro observa-se condição apropriada para a diferenciação dos tratamentos com as lâminas de irrigação adotadas.

Com relação às coberturas de solo, o solo nu se destacou, positivamente, dos demais tratamentos na associação com a lâmina de 50\% da $\mathrm{ET}_{\mathrm{o}}$, nos meses de março, junho e setembro. Nas lâminas de 100 e 150\% da ETo, o solo nu possibilitou um aumento na produtividade no período de dezembro a março, enquanto que, para o período de junho a setembro, esse tratamento, bem como a cobertura morta, foram os tratamentos que propiciaram uma maior produtividade. No período de dezembro a abril, houve elevadas precipitações na região; com isso, o solo nu pode ter possibilitado uma maior aeração para o sistema radicular, se comparado aos solos com as demais coberturas. Isso pode ter acarretado maior assimilação de nutrientes pelas plantas, favorecendo o aumento da produtividade para o respectivo tratamento. O tratamento com solo nu, também, pode ter proporcionado flutuações na disponibilidade de água no solo, gerando momentos de estresse hídrico moderado. A indução de estresse hídrico em videira é uma prática há muito utilizada para estimular a produção e melhorar a qualidade dos frutos (DAVIES et al., 2002).

A cobertura verde com leguminosa foi o tratamento que resultou em diminuição da produtividade na cultura do mamão. Esta leguminosa é muito promissora para o uso como cobertura verde de solo devido à sua resistência ao sombreamento e ao seu rápido desenvolvimento. Entretanto, a mesma não é adequada para a associação com a cultura de plantas de sistema radicular superficial, como o mamoeiro, pois esta leguminosa pode ter competido com o mamoeiro por água e nutrientes, competição esta que acarretou uma menor produtividade dessa cultura.

\section{CONCLUSÕES}

A MFM demonstrou uma sazonalidade ao longo do ano, sendo a sua maior incidência de ocorrência no mês de setembro. As variáveis de produção demonstraram ser altamente dependentes das variáveis climáticas; o alto acúmulo hídrico no solo acarretou diminuição de peso e número de frutos, o que, por conseqüência, ocasionou queda na produtividade da cultura. A cobertura morta demonstrou ser promissora para as variáveis em estudo. Entretanto, a cobertura verde resultou em uma menor produtividade da cultura, o que provavelmente ocorreu por competição de água e nutrientes entre a frutífera e a leguminosa.

\section{AGRADECIMENTOS}

Os autores agradecem à Caliman Agrícola S/A pelo apoio técnico e logístico; e à FAPERJ, ao CNPq e à FINEP pelo apoio financeiro.

\section{REFERÊNCIAS}

ALMEIDA, F.T. Resposta do mamoeiro (Carica papaya L.) do grupo solo a diferentes lâminas de irrigação no Norte Fluminense. 2000. 125f. Tese (Doutorado em Produção Vegetal) - Curso de Pós-graduação em Produção Vegetal, Universidade Estadual do Norte Fluminense.

ALMEIDA, F.T. et al. Expressão sexual do mamoeiro sob diferentes lâminas de irrigação na região Norte Fluminense. Revista Brasileira de Fruticultura, v.25, n.3, p.383-385, 2003.

ALVES, F.L. A cultura do mamão Carica papaya no mundo, no Brasil e no Estado do Espírito Santo. In: MARTINS, D.S., COSTA, A.F.S. A cultura do mamoeiro. Tecnologias de produção. Vitória, ES: Incaper, 2003. 497p.

AWADA, M.; IKEDA, W.S. Effects of water and nitrogen application on composition, growth, sugars in fruits, yield and sex expression of the papaya plants (Carica papaya L.). Honolulu. Hawaii: University of Hawaii, 1975. 16p. (Technical Bulletin, 33). 
BERILLI, S.S. Atributos qualitativos de frutos de mamoeiro híbrido - UENF/CALIMAN 01 - sob lâminas de irrigação e doses de nitrogênio e potássio. 2006. 84f. Tese (Mestrado em Produção Vegetal) - Curso de Pós-graduação em Produção Vegetal, Universidade Estadual do Norte Fluminense - UENF.

COUTO, F.A.D.; NACIF, S.R. Hibridação em mamão. In: BORÉM, A. (Org). Hibridação artificial de plantas. Viçosa, MG: Universidade Federal de Viçosa, 1999. p.307-329.

CRUZ, C.D. Programa genes (versão Windows), aplicativo computacional em genética e estatística. Viçosa: Universidade Federal de Viçosa, 2001. 648p.

CRUZ LIMA, H. Relações entre o estado nutricional, as variáveis do clima e a incidência da Mancha Fisiológica do mamão (Carica papaya L.) no Norte Fluminense. 2003. 62f. Tese (Mestrado em Produção Vegetal) - Curso de Pósgraduação em Produção Vegetal, Universidade Estadual do Norte Fluminense - UENF.

DAVIES, W.J. et al. Stomatal control by chemical signalling and the exploitation of this mechanism to increase water use efficiency in agriculture. New Phytologist, v.153, p.449460, 2002.

DOWNTON, W.J.S. Water relations of laticifers in Nerium oleander. Australian Journal of Plant Physiology, v.8, p.329-334, 1981.

ELOISA, M. et al. Skin freckles on solo papaya fruit. Scientia Horticulturae, v.58, p.31-39, 1994.
FRANKEL, R.; GALUN, E. Pollination mechanisms, reproduction and plant breeding. New York: Springer Verlag, Berlin: Heidelber, 1977. 281p.

IBGE. Capturado em: 15 jul. 2005. On-line. Disponível na internet: www.ibge.gov.br.

KAISER, C. et al. Some morphological and physiological aspects of freckle on papaya (Carica papaya L.) fruit. Journal of South African Society Horticulture Science, v.6, n.1, p.3740, 1996.

MARÍN, S.L.D.; GOMES, J.A. Técnicas de cultivo do mamão. In: SEMANA INTERNACIONAL DE FRUTICULTURA E AGROINDÚSTRIA, 7., 2000, Fortaleza, CE. Anais... Fortaleza: Frutal, 2000. 57p.

MARÍN, S.L.D.; SILVA, J.G.F. Aspectos econômicos e mercados para a cultura do mamoeiro do grupo Solo na região Norte do Espírito Santo. In: MENDES, L.G. et al. Mamão no Brasil. Cruz das Almas - BA: EUFBA/EMBRAPA - CNPMFT, 1996. p.7-21.

OLIVEIRA, M.A.B. Variações de algumas características fisiológicas dos frutos de mamoeiro (Carica papaya L.) em função de diferentes épocas de colheita. 1999. 73f. Dissertação (Mestrado em Produção Vegetal) - Curso de Pósgraduação em Produção Vegetal, Universidade Estadual do Norte Fluminense - UENF.

OLIVEIRA, J.G. et al. Mancha fisiológica do mamão: Uma perspectiva de obtenção de material genético tolerante. Revista Brasileira de Fruticultura, v.27, n.3, p.458-461, 2005. 